\title{
Double tagging clarifies post-release fate of great hammerheads (Sphyrna mokarran)
}

\author{
J. Marcus Drymon ${ }^{1,2^{*}}$ and R. J. David Wells $s^{3,4}$
}

\begin{abstract}
Background: Biotelemetry applications have advanced our understanding of many highly migratory species, but present a challenge for species that suffer high capture and/or post-release stress. Failing to accurately characterize post-release fate can obfuscate our understanding of animal movement patterns and complicate the development of effective conservation and management plans. The great hammerhead (Sphyrna mokarran) is a long-lived, highly migratory shark listed by the International Union for the Conservation of Nature as Endangered. Accordingly, we used a combination of tags designed to report horizontal position estimates and verify post-release fate, to examine movements of great hammerheads in the northern Gulf of Mexico.

Results: Between May and September 2016, three individuals (one male and two females) were equipped with both fin-mounted smart position and temperature transmitting (SPOT) tags and survivorship pop-off archival tags (sPAT) to provide information on post-release fate. Tagged sharks measured $187(F), 203(M)$, and $250(M) \mathrm{cm}$ total length. All three sharks surfaced daily, yet individuals showed variability in vertical habitat use, with maximum daily depths ranging from 5 to $98 \mathrm{~m}$. A single fin-mounted SPOT tag, attached to the smallest of the three sharks, reported position estimates over an 81-day period and moved a straight-line distance of approximately $400 \mathrm{~km}$; however, the other two fin-mounted SPOT tags failed to generate position estimates. All three sPAT tags indicated post-release survival. Final positions of the sPAT tags from the two largest sharks suggested restricted horizontal movements $(<35 \mathrm{~km})$.

Conclusions: Despite their demonstrated utility on other shark species that frequent the surface, fin-mounted SPOT tags may not be the best option for tracking great hammerheads. In addition, our findings illustrate the value of double-tagging animals under certain conditions; notably, over the short monitoring period of this study, one of the three sharks tagged may have been incorrectly presumed dead had only a fin-mounted SPOT tag been used.
\end{abstract}

Keywords: SPOT, sPAT, Post-release mortality, Movement

\section{Background}

Biotelemetry provides an approach for identifying movement patterns and post-release fate that can be used to inform conservation strategies, yet presents unique challenges for rare or endangered species. Despite increasingly sophisticated technology, electronic tags designed to communicate with the Argos system can fail to transmit position estimates [1]. Distinguishing these tag failures from animal mortality events is critical when examining populations in peril [2]. Double tagging, or

\footnotetext{
*Correspondence: marcus.drymon@msstate.edu

${ }^{1}$ Coastal Research and Extension Center, Mississippi State University, Biloxi, MS 39532, USA

Full list of author information is available at the end of the article

Fultist of author information is available at the end of the article
}

the application of complementary tag types designed to report both position estimates and post-release fate, is one approach for assessing post-release fate in the event of an Argos tag failure.

The great hammerhead (Sphyrna mokarran) is a highly migratory species of conservation concern. Great hammerheads are listed on the International Union for the Conservation of Nature (IUCN) red list as Endangered [3] and thought to be functionally extinct throughout parts of their historical range (e.g., Gulf of California, [4]). Despite a lack of a directed fishery in the northwest Atlantic Ocean, great hammerheads are caught incidentally in longline fisheries, where they suffer high at-vessel [5, 6] and post-release [7, 8] mortality. Given

C The Author(s) 2017. This article is distributed under the terms of the Creative Commons Attribution 4.0 International License (http://creativecommons.org/licenses/by/4.0/), which permits unrestricted use, distribution, and reproduction in any medium, provided you give appropriate credit to the original author(s) and the source, provide a link to the Creative Commons license, and indicate if changes were made. The Creative Commons Public Domain Dedication waiver (http://creativecommons.org/ publicdomain/zero/1.0/) applies to the data made available in this article, unless otherwise stated. 
their susceptibility to capture stress and subsequent postrelease mortality, the application of capture and tagging techniques must be approached cautiously.

Despite this documented vulnerability to capture stress, recent applications of biotelemetry have advanced our understanding of great hammerhead distribution, particularly in the western Atlantic Ocean. Using a combination of techniques, Guttridge et al. [9] identified large-scale migrations, seasonal residency, and site fidelity in great hammerheads tracked in Florida and the Bahamas. Similarly, Graham et al. [10] identified areas of core habitat use in relationship to marine protected areas along the coast of Florida and the Bahamas, but noted that their findings may not be representative of the entire population.

Less is known about the movements of great hammerheads in the Gulf of Mexico, despite this being a wellestablished part of their range. Great hammerheads are encountered via fishery-independent sampling in the northern Gulf of Mexico from March to November [11], across a broad range of sizes. Given the conservation status of this species, combined with our opportunistic access to them via ongoing fishery-independent sampling projects, we sought to investigate movements of great hammerheads in the northern Gulf of Mexico. However, their documented vulnerability to capture stress necessitated a cautious approach. Therefore, the objective of the current study was to investigate movement patterns in great hammerheads using a combination of biotelemetry tags; our double-tagging approach provided a means for collecting both position information and post-release survival verification.

\section{Methods}

Great hammerheads were captured during fishery-independent bottom longline sampling in the northern Gulf of Mexico in 2016 following methods outlined in [11, 12]. Briefly, a bottom longline consisting of $1.85 \mathrm{~km}$ of $4-\mathrm{mm}$ monofilament (545-kg test) mainline was set with 100 gangions. Gangions were $3.66 \mathrm{~m}$ in length and consisted of a longline snap and a 15/0 circle hook (Mustad model 39960D) baited with Atlantic Mackerel (Scomber scombrus). Each gangion was made of $3.66 \mathrm{~m}$ of $3-\mathrm{mm}$ monofilament (320-kg test). All bottom longlines were set (i.e., soaked) for $1 \mathrm{~h}$, during which time a Hydrolab MS5 data sonde and surveyor were used to record surface and bottom values for temperature $\left({ }^{\circ} \mathrm{C}\right)$.

Upon retrieval of the bottom longline, great hammerheads that could be boated safely were removed from the main line, and the circle hook severed with bolt cutters. Once boated, a saltwater hose was inserted into the mouth of the fish to provide ambient seawater across the gills. For each individual, sex, length (fork and stretch total in centimeters) and maturity stage (in males) were recorded. Maturity in males was assessed following [13]. Great hammerheads that were deemed to be in good condition (i.e., active and responsive, little or no visible external damage, [14]) were fitted with three tags: a conventional dart tag (Floy) and two satellite tags. Smart position and temperature transmitting tags (SPOT6, Wildlife Computers) were attached to the dorsal fin. Fin-mounted SPOT tags (hereafter SPOT tags) estimate position via Doppler-shift calculations, which are transmitted to the ARGOS satellite system when the saltwater switch is activated (i.e., when the tag breaks the surface). To examine whether a non-reporting SPOT tag was due to lack of surface events as opposed to post-release mortality, each great hammerhead was also tagged with a survivorship pop-off archival transmitting tag (sPAT tag, Wildlife Computers).

sPAT tags are specifically optimized to determine fate (alive or deceased) on animals post-release. These tags record daily minimum and maximum values for depth and temperature and indicate whether daily light levels varied; they are programmed to record these values for 30 days, then pop-off, and transmit data to the ARGOS satellite system. Raw data are analyzed in-house by Wildlife Computers, who provide a report indicating pop-off date, location, daily values for temperature and depth, an indication of daily changes in light, and fate. Fate (i.e., the reason for tag release) is used to infer survivorship and is classified into one of four categories: (1) completed deployment, (2) sinker, a tag attached to a sinking animal that releases at $1700 \mathrm{~m}$, (3) floater, a tag at the surface, and (4) sitter, a constant depth reading shallower than $1700 \mathrm{~m}$. Completed deployment (category 1) indicates survival, sinker and sitter (categories 2 and 4) indicate mortality, and floater (category 3 ) could be interpreted as either survival or mortality, based on inspection of depth data [15].

\section{Results}

Three great hammerheads (GH 1,2, and 3) were captured and tagged with conventional dart, SPOT, and sPAT tags in May, August, and September of 2016, respectively (Table 1). Water temperature (top/bottom) during tagging was $25 / 22,31 / 24$, and $29 / 29^{\circ} \mathrm{C}$, respectively. Tagged sharks were 187, 203, and $250 \mathrm{~cm}$ TL. All three sharks were tagged in the northern Gulf of Mexico and were released quickly (<120 s) (Fig. 1). The mean number of days at liberty measured by the sPAT tags was 24 days (ranging from 20 to 30 days), and daily changes in depth and light level were recorded for all three sharks. The SPOT tag attached to GH 2, the smallest individual $(187 \mathrm{~cm} \mathrm{TL})$, was the only SPOT tag that reported transmissions sufficient to estimate positions and did so over a 41-day period. 
Table 1 Size and tagging summary for great hammerheads $(n=3)$

\begin{tabular}{|c|c|c|c|c|c|c|c|c|c|c|c|c|}
\hline \multirow[t]{2}{*}{ GH } & \multirow[t]{2}{*}{ Sex } & \multirow[t]{2}{*}{$\mathrm{FL}$} & \multirow[t]{2}{*}{$\mathrm{TL}$} & \multirow[t]{2}{*}{$\begin{array}{l}\text { Tagging date } \\
\text { (2016) }\end{array}$} & \multirow[t]{2}{*}{$\begin{array}{l}\text { Pop-off } \\
\text { date (2016) }\end{array}$} & \multirow[t]{2}{*}{$\begin{array}{l}\text { Days at } \\
\text { liberty }\end{array}$} & \multirow[t]{2}{*}{$\begin{array}{l}\text { SPOT } \\
\text { transmission days }\end{array}$} & \multicolumn{2}{|c|}{$\begin{array}{l}\text { Tagging } \\
\text { Location }\end{array}$} & \multicolumn{2}{|c|}{ Pop-off location } & \multirow[t]{2}{*}{$\begin{array}{l}\text { Distance } \\
\text { traveled }(\mathbf{k m})\end{array}$} \\
\hline & & & & & & & & Lat & Lon & Lat & Lon & \\
\hline 1 & M & 185 & 250 & $5 / 13$ & $6 / 5$ & 23 & 0 & 29.66 & -88.30 & 29.65 & -87.94 & 35 \\
\hline 2 & $\mathrm{~F}$ & 141 & 187 & $8 / 4$ & $8 / 24$ & 20 & 81 & 30.04 & -87.69 & 28.62 & -91.33 & 387 \\
\hline 3 & $\mathrm{~F}$ & 150 & 203 & $9 / 16$ & $10 / 16$ & 30 & 79 & 30.30 & -88.38 & 30.24 & -88.60 & 22 \\
\hline
\end{tabular}

Great hammerhead 1 (GH 1) was an immature male $(250 \mathrm{~cm} \mathrm{TL})$ tagged on May 13, 2016. No positions were estimated from the SPOT tag. The sPAT deployed prematurely on June 5 after 23 days and was classified as a "floater." GH 1 made daily vertical movements from the surface $(0-2 \mathrm{~m})$ to an average depth of $37.2 \mathrm{~m}$ ( \pm 6.3 standard deviations, SD) and traveled a minimum straight-line distance (between the tagging and SPAT pop-off locations) of $35 \mathrm{~km}$. Given the consistent and substantial daily changes in depth over the 23-day period, we infer the fate of GH 1 as survival (Fig. 2a, Table 1).

Great hammerhead 2 (GH 2) was a female (187 cm TL) tagged on August 4. The SPOT tag on GH 2 reported positions to the ARGOS satellite system for 81 days. For the first 3 days post-release, the shark moved northeast $\sim 100 \mathrm{~km}$. The next SPOT tag transmission was on August 25, in agreement with the sPAT tag pop-off position. The sPAT deployed prematurely on August 24 after 20 days and was classified as a "sitter." GH 2 made daily vertical movements from the surface $(0 \mathrm{~m})$ to an average depth of $50.8 \mathrm{~m}( \pm 21.4 \mathrm{SD})$, with daily changes in depth up to 98 meters. GH 2 showed the greatest horizontal movement of the three tagged sharks, traveling a straight-line distance between the tagging and sPAT pop-off locations of $387 \mathrm{~km}$. Interestingly, the SPOT tag on GH 2 reported position estimates on September 14, approximately 3 weeks after the sPAT assigned the condition "sitter," a state typically indicative of mortality. Given the consistent and substantial daily changes in depth over a 20-day period, we infer the fate of GH 2 as survival (Fig. 2b, Table 1).

Great hammerhead 3 (GH 3) was a female (203 cm TL) tagged on September 16. While the SPOT tag transmitted data to ARGOS over a 79-day period, no transmissions were sufficient to estimate a position. The sPAT popped-off on October 16 after 30 days and was classified as a survival based on a complete deployment. $\mathrm{GH}$ 3 made daily vertical movements from the surface $(0 \mathrm{~m})$ to an average depth of $5.9 \mathrm{~m}( \pm 1.9 \mathrm{SD})$. This individual inhabited depths $6 \mathrm{~m}$ or less over $93 \%$ of the time, consistent with the bathymetry of Mississippi Sound. GH 3 showed the most restricted horizontal movements, traveling a straight-line distance between the tagging and sPAT pop-off locations of $22 \mathrm{~km}$ (Fig. 2c, Table 1).

\section{Discussion}

The application of complementary satellite tags provided insight into vertical and horizontal habitat use for great hammerheads that would not have been evident using a single tag type. Critically, one of the three tagged sharks may have been presumed dead if we had used SPOT tags alone. As such, despite their demonstrated utility on other shark species that frequent the surface, fin-mounted SPOT tags may not be the best option for tracking great hammerheads. Despite a low sample size $(n=3)$, our findings are noteworthy as they characterize movements from immature animals tagged in an area where we know comparatively little about the movements of this species.

Data from the sPAT tags showed all three great hammerheads made daily vertical movements from the surface to depth. Given the consistent use of surface waters and the exaggerated height of the dorsal fin to which the SPOT tag was attached, why were so few SPOT positions reported? To begin with, it is possible that the SPOT tags simply malfunctioned; for example, no SPOT transmissions were ever received for GH 1 . However, the SPOT tag on GH 2 transmitted to the ARGOS system, but not enough to generate a single position estimate, which requires at least two consecutive transmissions. This suggests that great hammerheads may not spend sufficient time (i.e., at least $90 \mathrm{~s}$ ) on the surface to allow a fin-mounted SPOT tag to communicate with the ARGOS system long enough to estimate positions. Given the previously successful application of towed SPOT tags on this species [10], towed packages may present the best option compared to fin-mounted SPOT transmitters.

An alternative explanation for why our fin-mounted SPOT tags failed to generate position estimates for sharks at the surface invokes a swimming behavior recently described for this species. Using a combination of accelerometer loggers, animal-borne video, and observations of aquarium-held sharks, Payne et al. [16] document repeated and prolonged swimming by great 


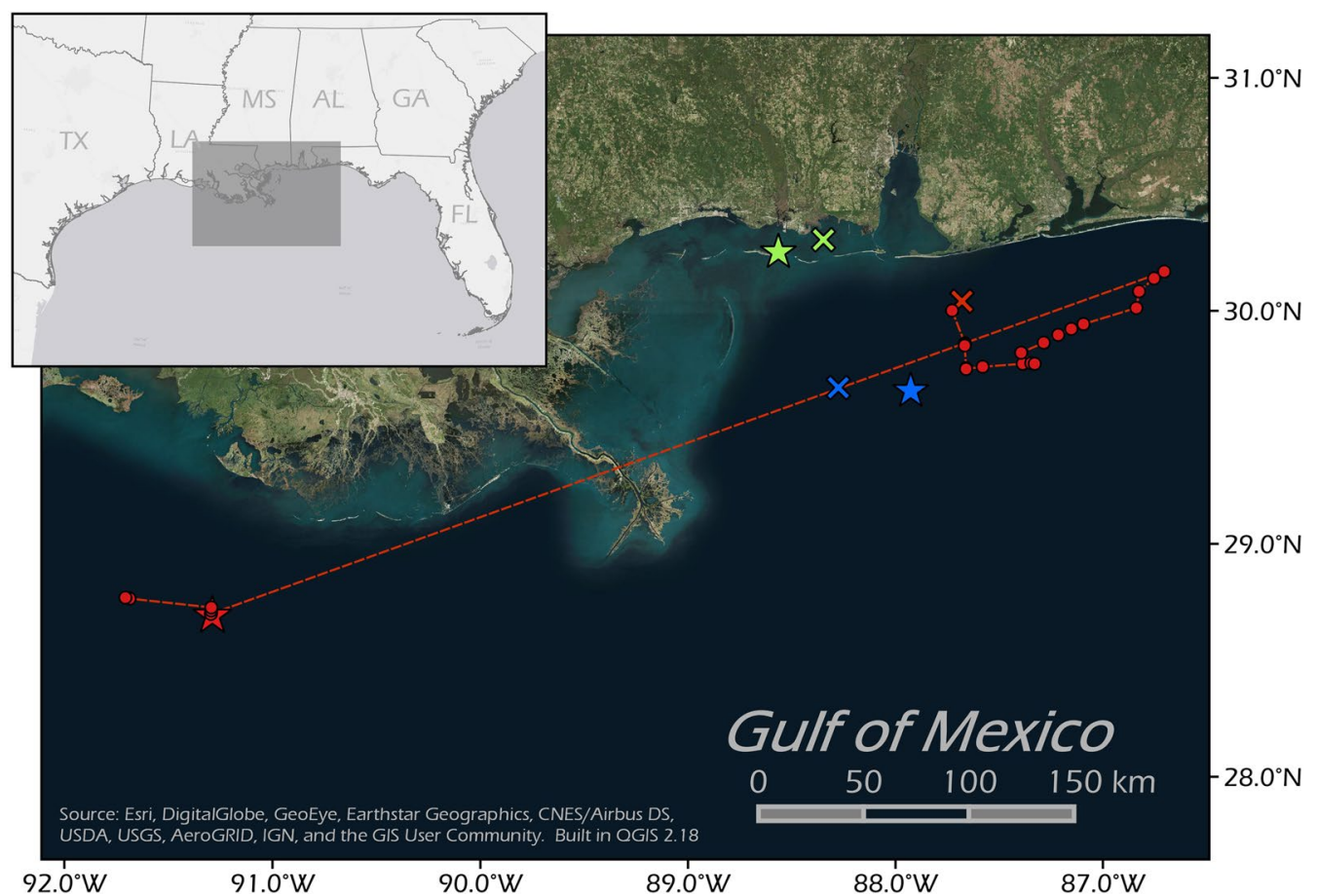

Fig. 1 Tagging location ( $\mathrm{x}$ ), sPAT pop-off location (star), and SPOT tag location estimates (circle) for GH 1 (blue), GH 2 (red), and GH 3 (green). Dashed lines connect position estimates from the SPOT tag. Inset shows US Gulf of Mexico

hammerheads at rolled angles between 50 and $75^{\circ}$. Using a hydrodynamic model and wind tunnel simulations, Payne et al. [16] estimate a reduction in drag forces that equates to an energetic savings of $\sim 10 \%$. Hence, while all great hammerheads tagged in this study frequented the surface, perhaps they were oriented such that the SPOT tag was still below the surface and thus unable to transmit. Alternatively, biofouling could have precluded the saltwater switch on the SPOT tag from functioning. Recent recoveries of fin-mounted SPOT tags from a scalloped hammerhead (Sphryna lewini) and tiger shark (Galeocerdo cuvier) in the northern Gulf of Mexico at liberty for less than 6 months revealed extensive biofouling which had prevented the tag from transmitting any location estimates (Drymon and Wells unpublished data). Previous studies demonstrate that SPOT tags are highly effective for tiger sharks, with reporting rates as high as $100 \%$ [7], but it may be that the highly productive waters of the northern Gulf of Mexico promote rapid biofouling compared to more oligotrophic waters like south Florida and the Caribbean. Regardless of the mechanism, finmounted SPOT tags appear to be a poor choice for examining short-term horizontal movements or post-release survivorship for great hammerheads in the northern Gulf of Mexico, despite their frequent use of surface waters.

Our findings add to a body of knowledge highlighting shallow water habitat use by great hammerheads. Over a thirty-day period, GH 3 used waters $6 \mathrm{~m}$ or less during $93 \%$ of the time at liberty. This finding is similar to the results presented by Hueter and Manire [17], who noted that great hammerheads along the southwest coast of Florida were only seen at depths shallower than $\sim 6 \mathrm{~m}$. In the US bottom longline fishery, great hammerheads are most commonly captured in waters less than $20 \mathrm{~m}$ [6]. Roemer et al. [18] described six instances of extreme shallow water habitat use by great hammerheads, five of which involved prey capture. Great hammerheads are known to frequent the shallow waters off south Florida in pursuit of tarpon (Megalops atlanticus) [19, 20]. Given the abundance of rays, a preferred prey item for this species $[21,22]$ in the shallow waters of the northern Gulf of Mexico, consistent use of shallow waters by great hammerheads in this region, may represent foraging behavior, although investigations into the feeding ecology of this species would be required to confirm this.

Generally, larger sizes afford increased vagility; as a consequence, many marine animals have larger home ranges as adults [23]. Great hammerheads are one of the largest-bodied species of predatory sharks [20] and can travel long distances over short periods of time [24], including movements exceeding $1500 \mathrm{~km}$ [9]. Acknowledging our relatively short tracking periods, two of the three great hammerheads tagged in this study showed movement less than $35 \mathrm{~km}$ between tagging and pop-off 

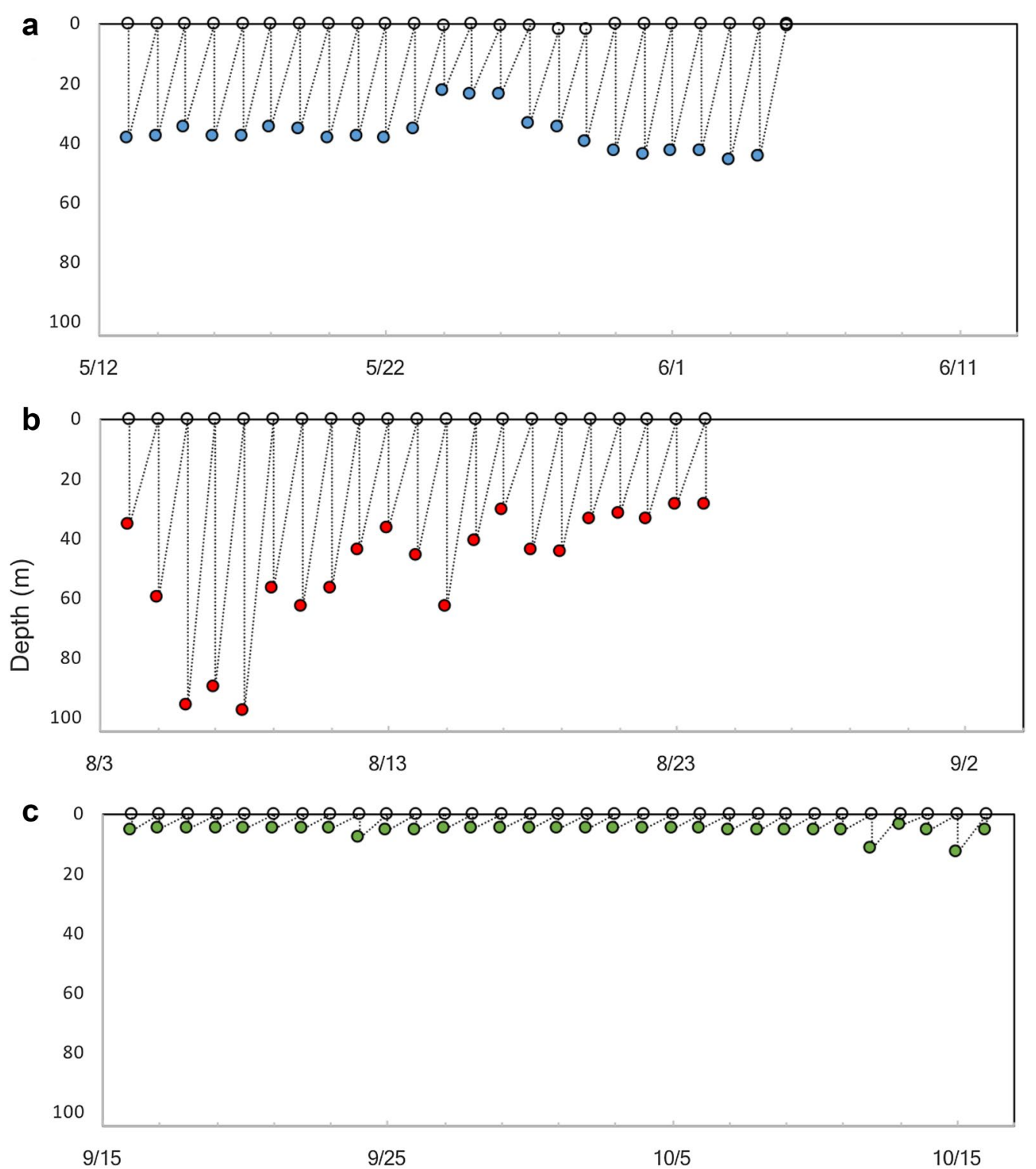

Month/day (2016)

Fig. 2 Tagging location (x), sPAT pop-off location (star) and SPOT tag location estimates (circle) for GH1 (a, blue), GH2 (b, red) and GH3 (c, green). Dashed lines connect position estimates from the SPOT tag. Inset shows U.S. Gulf of Mexico

locations. Counterintuitively, the smallest shark tagged (GH 2) moved nearly $400 \mathrm{~km}$ between tagging and pop-off locations; following what appeared to be clear eastward movement from Alabama into Florida, both fin-mounted SPOT and sPAT tags confirmed GH 2 west of the Mississippi River. Individual variation in habitat use has been demonstrated for other large predatory sharks, including tiger [25] and bull shark (Carcharhinus leucas, [26]). Thus, the individual variability in movement patterns illustrated in the current study appears to be common. Such high variability suggests that effective great hammerhead conservation and management plans will require movement data from individuals of all sizes and throughout the extent of their range. Interestingly, the longest horizontal movement in this study was demonstrated by a $187 \mathrm{~cm}$ TL female, likely the smallest satellite-tagged great hammerhead to date.

\section{Conclusions}

Mitigating the troubling trends in marine defaunation [23] will require immediate actions coupled with innovative approaches. In the case of great hammerheads, their 
IUCN status, susceptibility to at-vessel and post-release mortality, and high degree of specialization make them particularly vulnerable to over-exploitation [27]. While this study represents a limited number of fish monitored over a relatively short period, our findings highlight some of the difficulties inherent in understanding movements of highly migratory species. In particular, the application of mortality tags in addition to position tags provided the data necessary to interpret vertical movement, as well as verify post-release survivorship. Our findings provide valuable information to guide future studies seeking to understand movement and migration in this species.

\section{Authors' contributions}

$J M D$ and RJDW conceived the study, analyzed and interpreted the data, and wrote the manuscript. All authors read and approved the final manuscript.

\section{Author details}

${ }^{1}$ Coastal Research and Extension Center, Mississippi State University, Biloxi, MS 39532, USA. ${ }^{2}$ Mississippi-Alabama Sea Grant Consortium, Ocean Springs, MS 39564, USA. ${ }^{3}$ Department of Marine Biology, Texas A\&M University at Galveston, Galveston, TX 77553, USA. ${ }^{4}$ Department of Wildlife and Fisheries Science, Texas A\&M University, College Station, TX 77843, USA.

\section{Acknowledgements}

We thank Emily Seubert for tagging assistance in the field, Trey Spearman for Fig. 1, and Mark Albins for constructive comments that strengthened the manuscript. We are grateful to the Aquarium at Moody Gardens, Galveston Island, for their continued support in providing satellite tags.

\section{Competing interests}

The authors declare that they have no competing interests.

\section{Availability of data and materials}

The datasets used and/or analyzed during the current study are available from the corresponding author on reasonable request.

\section{Consent for publication}

Not applicable.

\section{Ethics approval and consent to participate}

All research was carried out in accordance with the University of South Alabama (USA) animal ethics protocol 974304. This research was approved by the Institutional Animal Care and Use Committee (IACUC), as well as State (Alabama) and Federal Authorities. All sharks were provided flowing seawater during tagging and were handled quickly and carefully.

\section{Funding}

Funding for the SPOT tags was provided by the Aquarium at Moody Gardens, Galveston Island.

\section{Publisher's Note}

Springer Nature remains neutral with regard to jurisdictional claims in published maps and institutional affiliations.

Received: 19 October 2017 Accepted: 30 November 2017 Published online: 14 December 2017

\section{References}

1. Hays GC, Bradshaw CJA, James MC, Lovell P, Sims DW. Why do Argos satellite tags deployed on marine animals stop transmitting? J Exp Mar Bio Ecol. 2007:349:52-60.
2. Cooke SJ. Biotelemetry and biologging in endangered species research and animal conservation: relevance to regional, national, and IUCN Red List threat assessments. Endanger Species Res. 2008:4(1-2):165-85.

3. Asber M, Bucal D, Cliff G, Denham J, Ducrocq M, Dulvy NK, Ferretti F, Graham R, Heupel MR, Lemine Ould Sisi M, Litvinov F, Morgan A, Seisay M, Soldo A, Stevens JD, Tous P, Valenti SV, Walls RHL, Martins P. 2-15. Sphyrna mokarran. The IUCN Red List of Threatened Species.

4. Pérez-Jiménez JC. Historical records reveal potential extirpation of four hammerhead sharks (Sphyrna spp.) in Mexican Pacific waters. Rev Fish Biol Fish. 2014;24(2):671-83.

5. Morgan A, Burgess GH. At-vessel fishing mortality for six species of sharks caught in the northwest Atlantic and Gulf of Mexico. Gulf Caribb Res. 2007;19(2):123-9.

6. Gulak SJ, de Ron Santiago AJ, Carlson JK. Hooking mortality of scalloped hammerhead Sphyrna lewini and great hammerhead Sphyrna mokarran sharks caught on bottom longlines. Afr J Mar Sci. 2015;37(2):267-73.

7. Gallagher AJ, Serafy JE, Cooke SJ, Hammerschlag N. Physiological stress response, reflex impairment, and survival of five sympatric shark species following experimental capture and release. Mar Ecol Prog Ser. 2014:496:207-18.

8. Ellis J, McCully P, Poisson F. A review of capture and post-release mortality of elasmobranchs. J Fish Biol. 2016;90:653-722.

9. Guttridge TL, Van Zinnicq Bergmann M, Bolte C, Howey-Jordan L, Kessel ST, Finger JS, Brooks JL, Winram W, Bond ME, Jordan LK, Cashman R. Philopatry and regional connectivity of the great hammerhead shark, Sphyrna mokarran in the US and the Bahamas. Front Mar Sci. 2017:4:3.

10. Graham F, Rynne P, Estevanez M, Luo J, Ault JS, Hammerschlag N. Use of marine protected areas and exclusive economic zones in the subtropical western North Atlantic Ocean by large highly mobile sharks. Divers Distrib. 2016;22:534-46.

11. Drymon JM, Powers SP, Dindo J, Dzwonkowski B, Henwood TA. Distributions of sharks across a continental shelf in the northern Gulf of Mexico. Mar Coast Fish. 2010:2(1):440-50.

12. Drymon JM, Carassou L, Powers SP, Grace M, Dindo J, Dzwonkowski B. Multiscale analysis of factors that affect the distribution of sharks throughout the northern Gulf of Mexico. Fish Bull. 2103;111(4):370-80.

13. Clark E, von Schmidt K. Sharks of the central gulf coast of Florida. Bull Mar Sci. 2007:15:13-83.

14. French RP, Lyle J, Tracey S, Currie S, Semmens JM. High survivorship after catch-and-release fishing suggests physiological resilience in the endothermic shortfin mako shark (Isurus oxyrinchus). Conserv Physiol. 2015:3(1):cov044.

15. Francis MP, Jones EG. Movement, depth distribution and survival of spinetail devilrays (Mobula japanica) tagged and released from purseseine catches in New Zealand. Aquat Conser Mar Freshw Ecosyst. 2017:27:219-36.

16. Payne NL, losilevskii G, Barnett A, Fischer C, Graham RT, Gleiss AC, Watanabe YY. Great hammerhead sharks swim on their side to reduce transport costs. Nat Commun. 2016;7:1-7.

17. Hueter RE, Manire CA. Bycatch and catch-release mortality of small sharks in the Gulf coast nursery grounds of Tampa Bay and Charlotte Harbor. Mote Marine Technical Report No. 368 (Final report to NOAA/NMFS, MARFIN Project NA17FF0378-01). 1994; 183pp.

18. Roemer RP, Gallagher AJ, Hammerschlag N. Shallow water tidal flat use and associated specialized foraging behavior of the great hammerhead shark (Sphyrna mokarran). Mar Freshw Behav Physiol. 2016;49(4):235-49.

19. Ault JS, Humston R, Larkin MF, Perusquia E, Farmer NA, Luo J, Zurcher N, Smith SG, Barbieri LR, Posada JM. Population dynamics and resource ecology of Atlantic tarpon and bonefish. In: Ault JS, editor. Biology and management of the world tarpon and bonefish fisheries. Boca Raton: CRC Press; 2007. p. 217-58.

20. Castro J. The sharks of north America. Oxford: Oxford University Press; 2010.

21. Strong WR, Snelson FF, Gruber SH. Hammerhead shark predation on stingrays: an observation of prey handling by Sphyrna mokarran. Copeia. 1990:3:836-40.

22. Chapman DD, Gruber SH. A further observation of the prey-handling behavior of the great hammerhead shark, Sphyrna mokarran: Predation upon the spotted eagle ray, Aetobatus narinari. Bull Mar Sci. 2002;70(3):947-52. 
23. McCauley DJ, Pinsky ML, Palumbi SR, Estes JA, Joyce FH, Warner RR. Marine defaunation: animal loss in the global ocean. Science. 2015;347(6219):1255641.

24. Hammerschlag N, Gallagher AJ, Lazarre DM, Slonim C. Range extension of the Endangered great hammerhead shark Sphyrna mokarran in the Northwest Atlantic: preliminary data and significance for conservation. Endanger Species Res. 2011;13(2):111-6.

25. Vaudo JJ, Wetherbee BM, Harvey G, Nemeth RS, Aming C, Burnie N, Howey-Jordan LA, Shivji MS. Intraspecific variation in vertical habitat use by tiger sharks (Galeocerdo cuvier) in the western North Atlantic. Ecol Evolut. 2014;4(10):1768-86.
26. Matich P, Heithaus MR. Individual variation in ontogenetic niche shifts in habitat use and movement patterns of a large estuarine predator (Carcharhinus leucas). Oecologia. 2015;178(2):347-59.

27. Gallagher AJ, Hammerschlag N, Shiffman DS, Giery ST. Evolved for extinction: the cost and conservation implications of specialization in hammerhead sharks. Bioscience. 2014;64(7):619-24.

\section{Submit your next manuscript to BioMed Central and we will help you at every step:}

- We accept pre-submission inquiries

- Our selector tool helps you to find the most relevant journal

- We provide round the clock customer support

- Convenient online submission

- Thorough peer review

- Inclusion in PubMed and all major indexing services

- Maximum visibility for your research

Submit your manuscript at

www.biomedcentral com/submit 